\title{
Bimetalismo, Ouro, Prata e Gresham: Uma Contribui- ção para o Estudo da Circulação de Moeda-Metálica no Brasil no Século XVIII
}

\author{
Fernando Carlos Greenhalgh de Cerqueira Lima \\ Professor - Universidade Federal do Rio de Janeiro (UFRJ) - Campus da Praia Vermelha \\ Endereço para contato: Av. Pasteur, $n^{\circ} 250$, andar térreo - Urca - Rio de Janeiro - RJ \\ CEP: 22290-240 - E-mail: fcgclima@terra.com.br
}

Recebido em 18 de dezembro de 2012. Aceito em 23 de janeiro de 2013.

\begin{abstract}
Resumo
A grande cunhagem de moedas de ouro no século XVIII contribuiu para elevar o nível de monetização do Brasil, mas não poderia solucionar definitivamente os problemas típicos de um sistema bimetálico, em particular aqueles decorrentes da lei de Gresham, segundo a qual "a moeda má expulsa de circulação a moeda boa".

No início daquele século, a prata comprava mais ouro no mercado do que nas casas da moeda. Havia incentivo, portanto, de entesourar a prata, ou exportá-la. A partir da década de 1760, a queda na produção de ouro e o concomitante aumento da oferta de prata vinda de Buenos Aires reduziram a discrepância entre os valores oficiais e de mercado do ouro e da prata. No início do século XIX, em função da maior valorização de mercado do ouro, a prata estaria se tornando a "moeda má", prestes a expulsar a de ouro.
\end{abstract}

\section{Palavras-Chave}

bimetalismo, lei de Gresham, moeda-metálica, Brasil colonial, circulação monetária

\begin{abstract}
The large amount of gold coinage at the Brazilian mints in the first half of the XVIII century contributed to raise the level of monetization, but was not sufficient to solve definitively the typical problems brought about by bimetallism, particularly those due to the consequences of Gresham's Law, according to which "bad money drives out good". At the beginning of that century, silver bought more gold in the market than at the mints. Therefore, there was an incentive to hoard silver, or to export it. After the 1760's, the falling gold production, couple with the growing inflow of silver arriving from Buenos Aires reduced slowly the gap between the market and official prices of gold and silver. By the beginning of the nineteenth century, thanks to the rise in the market price of gold, silver had become "bad money", ready to drive out gold from circulation.
\end{abstract}

\section{Keywords}

bimetallism, Gresham's law, metallic currency, colonial Brazil, monetary circulation

\section{JEL Classification}

N16, N26 


\section{Introdução}

O estudo da circulação monetária no Brasil colonial tem recebido crescente atenção dos historiadores econômicos. Em relação ao período anterior à exploração de ouro nas Minas Gerais, a noção de que havia escassez generalizada de moeda vem sendo questionada. ${ }^{1}$ A escassez de numerário, de que tantas vezes se queixaram os colonos e autoridades locais, era eventual, e quase sempre poderia ser atribuída a quedas dos preços do açúcar e do tabaco nos mercados europeus, ${ }^{2}$ o que levava os comerciantes portugueses a preferirem trocar as mercadorias que traziam da metrópole por moeda, ao invés de praticar o escambo. ${ }^{3}$ Quanto ao século XVIII, tem sido ressaltado o fato de que a cunhagem de espécies de ouro pelas casas da moeda certamente contribuíram para elevar o grau de monetização da colônia, além de acelerar a integração econômica inter-regional. Enquanto foi abundante, a oferta de ouro teria atendido às necessidades do rápido crescimento da demanda por este tipo de moeda. Como explica Carrara (2010, p. 237),

[a] circulação mercantil constituída pela produção de ouro não se circunscreveu ao território da capitania. A mineração fecundou os circuitos mercantis no interior do Brasil, e trouxe para sua órbita de influência gêneros produzidos em áreas muito longínquas, como Sal de Pilão Arcado, na Bahia, ou cavalos e mulas, do sul do Brasil. Foi exatamente esta irrigação de moeda pelo interior do Brasil que possibilitou a constituição de extensos espaços econômicos.

Entretanto, cabe indagar se este aumento substancial da oferta de ouro (amoedado e em pó) a partir do final do século XVII teria solucionado algumas das deficiências na circulação monetária, ou mesmo se teria contribuído para criar outras. Como se sabe, qualquer sistema monetário exige a circulação de meios de pagamento

1 Ver, por exemplo, Sampaio (2003); Carrara (2005; 2010), Lima (2005a; 2005b), Puntoni (2010). Estes estudos referem-se especificamente ao Estado do Brasil, uma vez que no Estado do Maranhão e Grão-Pará a circulação de moeda metálica foi proibida até meados do século XVIII.

2 "Chama a atenção o fato de que não há registros de queixas de falta de moeda nas conjunturas de alta dos preços de açúcar" (Carrara, 2005, p.13).

3 Van Der Wee (1977) destaca que a prática do escambo era comum no início da Idade Moderna não apenas em transações domésticas, mas também no comércio internacional. 
com amplas diferenças de denominações. Nos dias de hoje, esse é um problema superado, já que a autoridade monetária pode emitir notas (papel-moeda) de valores os mais diversos, e depósitos à vista podem ser transferidos em vultosas quantias com a precisão de centavos.

Por outro lado, em um sistema monetário baseado em moeda metálica, como o que caracterizou o nosso período colonial, prover a economia com moedas tanto de baixo como de elevado valor nominal era um problema fundamental a ser resolvido. O meio circulante era composto por moedas de ouro, prata e cobre que cumpriam funções distintas, relacionadas, por um lado, com seus valores extrínsecos (nominais) e, por outro lado, com a relação entre seus valores intrínseco e extrínseco. As moedas de ouro não tinham utilidade em pagamentos de pequena monta; no outro extremo, as de cobre nem mesmo podiam ser utilizadas, legalmente, em pagamentos acima de determinados valores, ${ }^{4}$ enquanto que moedas de prata, de valor intermediário, podiam servir a ambos os propósitos. Isso significava que, mesmo sendo cunhadas quantidades significativas de moedas de ouro, podia haver "escassez de moeda", como ressalta V. M. Godinho, referindo-se à situação de Portugal no início do século XVIIII:

As chegadas de ouro, se trazem alívio à balança comercial, não são, de modo algum, a solução de todos os problemas. A circulação corrente continua a ser a da prata, pois as moedas de ouro são demasiado valiosas para as compras correntes no mercado, interessando o comércio internacional, e não o regional ou local. (Godinho, 1983, p. 727)

Não apenas em Portugal, mas também em outras partes da Europa, graves problemas monetários foram sentidos no início da Idade Moderna. Grande parte da literatura aponta o padrão monetário (bimetálico) então adotado como responsável por diversos desequilíbrios. Um dos problemas do bimetalismo mais discutidos é a chamada lei de Gresham que, em sua versão mais difundida, prevê que "a moeda má expulsa de circulação a moeda boa". Outro problema do bimetalismo, levantado mais recentemente, diz respeito à sua tendência de provocar escassez crônica de moeda de baixo valor

4 Em 1699, o poder liberatório das moedas de cobre foi fixado em um tostão ou cem réis (Sousa, 2006). 
(moeda de troco), problema que só teria sido resolvido com a adoção do monometálico padrão ouro, na segunda metade do século XIX. Tal problema estava associado às pequenas moedas de prata, às de bilhão (prata misturada com muito cobre) e às moedas exclusivamente de cobre.

Este trabalho pretende contribuir para o debate sobre a circulação monetária no Brasil no século XVIII, analisando as duas questões mencionadas acima, que estariam inter-relacionadas: os efeitos da lei de Gresham sobre a oferta de moedas de prata eventualmente ocasionados pela produção de ouro e, secundariamente, o problema específico relativo à circulação de moedas de baixo valor. A próxima seção resume o debate teórico. A terceira seção busca entender os possíveis impactos da produção de ouro nas Minas e das alterações na legislação monetária decretadas pela metrópole sobre a circulação de moedas prata ao longo do século XVIII. A quarta seção conclui.

\section{Bimetalismo e Lei de Gresham}

O padrão monetário adotado na Europa e nas colônias americanas nos séculos XVI a XVIII pode ser genericamente descrito como bimetálico. De acordo com Kemmerer (1935, p.83),

O verdadeiro bimetalismo [...] existe quando um país abre suas casas da moeda para que cunhem livre e ilimitadamente ouro e prata a uma taxa fixa equivalente chamada de taxa de cunhagem, oferecendo às moedas de ambos os metais [...] um poder legal idêntico. As moedas que gozam do privilégio da livre cunhagem geralmente possuem poder liberatório ilimitado.

Em termos práticos isto significava dizer que eram os agentes econômicos que determinavam a quantidade de moeda cunhada nas casas da moeda. ${ }^{5} \mathrm{O}$ governante poderia criar incentivos para atrair

5 Embora a quantidade de moeda cunhada fosse decidida pelos agentes privados, o Estado podia alterar, a qualquer momento, por decreto, a quantidade de unidades de conta, através de "levantamentos da moeda" ou "rebaixamentos". Para "levantar" a moeda, e assim aumentar a quantidade nominal de meio circulante, bastava aumentar o valor extrínseco das moedas 
metais às oficinas de moedas, por exemplo, aumentando o preço oferecido. ${ }^{6}$ Nesse caso, se o valor intrínseco (características físicas como peso, pureza, etc.) das moedas a serem cunhadas não fosse alterado, isso representaria uma desvalorização da unidade de conta. Desde a Idade Média até fins do século XVII, em toda a Europa os estados alteravam com frequência o valor oficial (valor extrínseco) ou o valor intrínseco de suas moedas. A partir do século XVIII, o recurso às desvalorizações da moeda passou a ser praticado de maneira moderada. ${ }^{7}$ Em Portugal, como mencionado acima, o valor do ouro permaneceu constante entre 1688 e 1822, e o valor da prata foi modificado apenas duas vezes (em 1734 e em 1747) nesse período.

Até hoje se discute a viabilidade do bimetalismo. Para os seus defensores, ${ }^{8}$ o sistema se autorregulava, no sentido de que o preço oficial estabiliza o preço de mercado, como sucintamente explica, mas sem concordar com o argumento, Charles Kindleberger:

Se o preço de mercado do ouro cai, aumenta a quantidade de ouro e diminui a quantidade de prata levada à casa da moeda, fazendo com que suba o valor de mercado do ouro e caia o valor da prata até que se restabeleça o valor de mercado ao valor da casa da moeda. (Kindleberger, 1984, p. 56)

Milton Friedman, ao resenhar o debate entre os adeptos do bimetalismo e os do padrão-ouro, procurou mostrar que, sob certas condições, a circulação simultânea de moedas ouro e de prata podia de fato ocorrer por longos períodos. ${ }^{9} \mathrm{Na}$ França, por exemplo, o padrão

em circulação sem alterar seu valor intrínseco. O mesmo acontecia (ainda que com menor frequência) no sentido contrário, como explica didaticamente Velde (2006), ao narrar fatos ocorridos na França em meados da década de 1720.

6 Essas "manipulações da moeda" podiam se restringir a apenas um dos metais, ou aos dois metais simultaneamente.

7 A explicação mais aceita para isso é que as chamadas "revoluções financeiras" dos séculos XVII e XVIII permitiram que os Estados europeus não mais necessitassem tanto de ganhos de senhoriagem. No caso específico português, teria pesado também o interesse dos grandes comerciantes e dos credores em geral Sousa (2006).

8 Ver, em particular, Fisher (1922). Flandreau (2002) reapresenta esse argumento.

9 Milton Friedman retomou esse debate ao discutir a ideia de que o fim do bimetalismo nos EUA poderia ser considerado um equívoco e defender aqueles que classificaram como "crime" a desmonetização da prata pelo Congresso americano em 1873 (Friedman,1990). Sobre o tema, ver ainda Velde (2002); para um estudo do abandono do bimetalismo na França, também em 1873, ver Flandreau (1996). 
bimetálico foi mantido desde o final do século XVIII até 1873, apesar das fortes oscilações ocorridas na oferta dos dois metais nesse período. A tendência ao monometalismo decorrente dos efeitos da lei de Gresham seria menos determinante quanto maior fosse o tamanho da área monetária, quanto maior fosse o uso de moedas metálicas em relação ao total dos meios de pagamento, quanto maiores fossem os custos de transação das operações de arbitragem, entre outros fatores. ${ }^{10}$ Todavia, pondera Kindleberger, ao longo da história o processo autorregulatório do bimetalismo teria ocorrido, na melhor das hipóteses, poucas vezes: "Ao invés de o preço estabelecido pela casa da moeda ter estabilizado o preço de mercado, este, em resposta basicamente a mudanças na oferta desses metais, desestabilizou o preço da casa da moeda através do funcionamento da lei de Gresham" (Idem).

Em sua essência, a versão mais difundida da chamada lei de Gresham estabelece que "a moeda má expulsa de circulação a moeda boa". "Moeda má" é aquela à qual o governante atribui um valor nominal (valor extrínseco) maior do que o valor intrínseco (de mercado) da moeda. "Moeda boa", por sua vez, é aquela cujo valor intrínseco é maior do que o valor extrínseco. Em outras palavras, a moeda má é aquela que é oficialmente sobrevalorizada e moeda boa a que é oficialmente subvalorizada. ${ }^{12}$ De acordo com Mundell (1998), a lei de Gresham é uma lei natural da economia: racionalmente os agentes preferem usar uma moeda mais barata e retirar de circulação a moeda mais cara se ambas são intercambiáveis pelo mesmo preço. Se o valor de mercado de determinado metal é superior ao valor oficial (portanto, aquele aceito na Casa da Moeda), é natural que os agentes econômicos vendam a peso no mercado (ou entesourem) as peças cunhadas neste metal.

O sistema bimetálico tendia, portanto, ao monometalismo, já que os governos pouco podiam fazer para controlar as taxas de mercado, que eram fortemente influenciadas pelos fluxos internacionais de metais. Talvez o exemplo histórico mais citado na literatura de uma

\footnotetext{
${ }^{10}$ Ver, por exemplo, Bordo (1992).

11 "Sir Thomas Gresham foi um hábil corretor de câmbio, leal servidor da rainha Elizabeth I, filantropo e homem rico, mas não foi ele quem descobriu a instabilidade inerente quando se tem duas ou mais moedas. A falsa atribuição [...] se deve a Henry D. Macleod, um economista do século XIX..." (Kindleberger, 1984, p. 57).

${ }^{12}$ Para Mundell (1998), se a relação ouro/prata não fosse fixada oficialmente, a "lei" teria sentido inverso, ou seja, a "moeda boa" expulsaria de circulação a "moeda má", citando os exemplos da libra inglesa no século XIX e do dólar americano dos dias de hoje.
} 
aplicação prática da lei de Gresham seja o da "grande recunhagem" realizada na Inglaterra em 1696, e que deixou registrado o debate entre Locke e Lawndon. ${ }^{13}$ Os ingleses estavam então em guerra com a França e o pagamento dos soldados era feito no continente. As moedas de prata em circulação na Inglaterra (usadas nestes pagamentos) estariam cerca de 50\% abaixo de seu peso oficial, o que significava grande prejuízo para os cofres da Coroa inglesa, que arrecadava impostos com moeda de baixo valor intrínseco e tinha de pagar soldados com boas moedas. Decidiu-se então pela recunhagem de todas as moedas de prata, mantendo seu valor nominal, como proposto por Locke; o resultado foi que as novas moedas valiam mais a peso do que pelo seu valor nominal, o que incentivava seu entesouramento.

A tese da autorregulação do mercado admite que o problema poderia ser corrigido através de operações de arbitragem. Neste caso específico, não só o valor intrínseco das moedas de prata na Inglaterra era superior ao seu valor extrínseco, mas, além disso, em outros países europeus a relação entre os valores do ouro e da prata era de 1:15, enquanto que na Inglaterra era de 1:15,5. Portanto, era possível obter ganhos de arbitragem da seguinte maneira: de posse de 10 moedas de ouro, por exemplo, uma pessoa podia obter 155 moedas de prata na Casa da Moeda da Inglaterra. Atravessava o Canal da Mancha e trocava 150 daquelas moedas de prata por dez moedas de ouro, obtendo cinco moedas de prata de lucro. Voltava para a ilha, e recomeçava o processo entregando as dez moedas de ouro na Casa da Moeda, pelas quais receberia 155 moedas de prata. Retornava então ao Continente, para dar seguimento à troca de prata por ouro. ${ }^{14}$ Embora teoricamente tal processo devesse levar a uma diminuição da oferta de prata e, portanto, a um aumento do seu valor de mercado na Inglaterra (com a consequente queda relativa no valor do ouro, revertendo o processo), os fatos não comprovaram a teoria. A recunhagem efetuada sem a concomitante alteração do valor nominal fez com que a moeda de prata (moeda "boa") deixasse de circular na Inglaterra. ${ }^{15}$

\footnotetext{
${ }^{13}$ Mundell (1998) resume a "grande recunhagem". Sobre a controvérsia entre Locke e Lawndes, além do texto citado de Robert Mundell, ver, por exemplo, Kelly (1991).

${ }^{14}$ De acordo com Poitras (2009), o uso de letras de câmbio facilitava as operações de arbitragem ao reduzir os custos de transação e os riscos em comparação com o uso de barras e moedas.

${ }^{15}$ Muitos autores atribuem à recunhagem, da maneira como foi executada, a adoção (involuntária) do padrão-ouro pela Inglaterra.
} 
Outro método que teria sido empregado para mitigar os efeitos da lei de Gresham era o de reduzir (através do cerceio, de falsificações, e outros recursos) o peso das moedas de determinado metal em circulação cujo valor de mercado fosse superior ao extrínseco, e com isso aproximando os dois valores. Este teria sido um método corriqueiro, que poderia ser distinguido da simples fraude no sentido de que o cerceio seria a forma encontrada pela sociedade de manter a moeda em circulação. Ao longo da história, foi o que ocorreu com as moedas de menor valor nominal.

No final da Idade Média e início da era moderna, os governos europeus davam às moedas de prata de menor valor um tratamento diferenciado. Enquanto que as moedas de ouro (e as de prata de valor unitário elevado) tinham seu valor extrínseco (e muitas vezes também intrínseco) mantido constante, as moedas menores sofriam frequentes desvalorizações. ${ }^{16}$ Carlo Cipolla deixa claro que o bimetalismo causaria um tipo de problema, também decorrente da lei de Gresham, mas que é relacionado especificamente aos papéis diferentes desempenhados, por um lado, pelas moedas de maior valor intrínseco de circulação internacional, que eram as moedas de ouro e as grandes moedas de prata e, por outro lado, as moedas que serviam para pequenas transações cotidianas, ou "moedas de troco": ou haveria escassez de moedas "aristocráticas" (moedas de ouro e grandes moedas de prata), ou haveria escassez de moedas de troco (moedas de prata de baixo valor, moedas de cobre e "bilhão", que era uma moeda de prata "escura", em cuja composição predominava o cobre). Nas palavras de Cipolla (1967, p. 27),

Nenhuma sociedade que usa tanto o ouro como a prata para efeitos de cunhagem pode manter um sistema monetário estável e satisfatório se ela cunha moedas de troco com conteúdo metálico igual ao seu valor na circulação. Neste caso, as contínuas flutuações nos preços de mercado do ouro, da prata e do cobre causam um de dois efeitos: obrigam as autoridades a mudar continuamente as relações de cunhagem $e$ as taxas de câmbio entre moedas grandes $e$ pequenas; ou levam a que um dos dois tipos de moeda desapareça de circulação.

${ }^{16}$ Glassman \& Redish (1988) analisam as desvalorizações ocorridas na França e na Inglaterra no início da Idade Moderna. Peres (1934) apresenta um estudo detalhado do caso português. 
Para Cipolla, a experiência histórica mostrou que a escassez de moeda acontecia principalmente com as moedas de troco, dado que, no padrão bimetálico típico, os governos ordenavam a cunhagem de moedas, tanto as moedas grandes como as de troco, com valor intrínseco igual ao valor extrínseco. A "fórmula padrão" capaz de solucionar tal problema era mencionada em qualquer livro-texto de economia: o governo deveria cunhar moedas de troco cujo valor como mercadoria fosse inferior ao seu valor monetário; essa cunhagem não deveria ser superior ao necessário; e esta moeda teria de ser conversível, ao par, à unidade de conta (Cipolla, idem).

Mais recentemente, Thomas Sargent e François Velde (S\&V) retomaram a tese levantada por Cipolla, ${ }^{17}$ procurando demonstrar que a "fórmula padrão" foi adotada a partir do século XIX, graças (i) aos avanços tecnológicos na produção de moedas que possibilitaram a emissão de moeda de troco cujo custo de falsificação fosse elevado, ${ }^{18}$ e (ii) ao processo de aprendizagem das autoridades monetárias que, ao longo dos séculos, finalmente compreenderam a importância de restringir a emissão monetária às "necessidades de negócio" (Sargent \& Velde, 1998). ${ }^{19}$ Desta forma teria sido aberto o caminho para a implantação do padrão ouro e para a posterior aceitação da moeda fiduciária.

${ }^{17}$ A expressão usada por Cipolla foi petty coins. Sargent \& Velde adotaram outra (small change). Que moedas, entre as que circulam de fato, enquadrar- se-iam à definição de "moeda de troco" é uma questão em aberto, que depende, na prática, das condições específicas de cada região. No Brasil, por exemplo, as patacas eram usadas cotidianamente. Na Ásia, pelo menos no início do século XVII, eram consideradas moedas nobres, para uso internacional (Wolters, 2006), o que talvez se explique pelo fato de que, naquele período, a prata fosse um metal relativamente mais valioso naquela região.

$18 \mathrm{~S} \& V$ seguem, neste aspecto, uma tese desenvolvida por Angela Redish, segundo a qual "a Inglaterra abandonou o bimetalismo em 1816 porque um padrão ouro com cunhagem de moedas de prata fiduciárias oferecia a possibilidade de um meio de troca com moedas de baixa e elevada denominação circulando concomitantemente. O padrão ouro vingou porque a nova tecnologia empregada pela Casa da Moeda era capaz de fabricar moedas que os falsificadores não poderiam copiar a custos baixos e porque a Casa da Moeda aceitou a responsabilidade de conversão daquelas moedas fiduciárias". Redish (1990, p. 805).

${ }^{19}$ Desde então, a validade da tese de S\&V tem sido testada para um grande número de países, com resultados mistos. Por exemplo, Volkart (2006) discorda do modelo de S\&V ao analisar o caso europeu do final do período medieval, enquanto Selgin (2003) não encontra evidência de que a "fórmula padrão" tenha sido adotada na Inglaterra; por outro lado, Álvarez-Nogal (2008) argumenta que o modelo se aplica ao caso da Espanha. Ennis (2006), escrevendo sobre a Argentina, concorda que havia falta de moeda de troco no final do período colonial, mas frisa que ainda não há dados suficientes para provar ou refutar a teoria de $S \& V$ sobre as razões desta falta e a forma de solucioná-la. 


\section{A Lei de Gresham e a Circulação Monetária no Brasil no Século XVIII}

\subsection{Uma Visão Geral}

Em 1688, antes, portanto, da descoberta das minas de ouro no Brasil, Portugal empreendeu uma profunda reforma monetária. A Coroa determinou a recunhagem das moedas de prata e elevou os preços tanto da prata como do ouro em $20 \%$. O marco de ouro de 22 quilates passava a valer, amoedado, 102.400 réis, enquanto o marco de prata de 11 dinheiros valia, amoedado, 6.360 réis. A relação ouro/ prata oficial ficou estabelecida em 1:15,5. A nova disposição monetária passaria a valer tanto no Reino como nas "conquistas", nas quais a moeda de prata correria a peso. ${ }^{20}$

Em 1694, as autoridades metropolitanas autorizaram a criação de uma casa da moeda em Salvador, em grande parte em resposta às constantes queixas sobre escassez de moeda que seria aguçada com a adoção da "moeda a peso". Segundo cálculos do governador-geral Câmara Coutinho, ${ }^{21}$ o Brasil precisava de uma casa da moeda para cunhar um total de dois milhões de cruzados (equivalentes a 800 mil contos de réis), metade para a Bahia, 600 mil cruzados para Pernambuco e 400 mil cruzados para o Rio de Janeiro. Entretanto, a Casa da Moeda de Salvador, que funcionou entre 1695 e 1697, emitiu um total de 921 mil contos. Depois transferida para o Rio de Janeiro e Recife, a Casa da Moeda cunhou mais 868 mil e 428 mil contos, respectivamente. O somatório de todas as emissões de moeda dessa Casa da Moeda "ambulante" foi, portanto, quase três vezes superior ao que o governador considerava suficiente para "girar os negócios" no Brasil. Em relação à moeda prata, foi cunhado o total aproximado de 1.500 contos. Para se ter uma ideia do que este total representava, vale a comparação com os cerca de 2.500 contos que circulavam em Portugal nos primeiros anos do século XVIII, segundo as estimativas de Rita Martins de Sousa. ${ }^{22}$

\footnotetext{
${ }^{20}$ Esta foi a última grande reforma executada em Portugal até a introdução do papel-moeda, em 1797 (Sousa, 2006). O preço do ouro em réis permaneceu inalterado até 1822.

${ }^{21}$ Representação datada de 4 de julho de 1692, citada em Golçalves (1984, pp. 54-55).

22 Sousa (2007, p.314, Anexo 4.2. do capítulo IV).
} 
Esta quantidade (de certa forma surpreendente) de metais levada à Casa da Moeda provoca uma reflexão: de onde teria vindo tanta prata (e, em menor escala, ouro) para ser cunhada nesses estabelecimentos? A resposta mais plausível é que estes metais estavam entesourados. ${ }^{23}$ Como até então o meio circulante era composto quase exclusivamente por moedas de prata, é possível supor que a ação da lei de Gresham mantinha em circulação as moedas de prata mais cerceadas (moeda má), já que possuíam o mesmo valor extrínseco que as menos cerceadas (moeda boa). Vale ressaltar que toda aquela moeda cunhada na Casa da Moeda "ambulante" era provincial, com peso $10 \%$ inferior ao da moeda circulante em Portugal, ou seja, havia incentivo a não exportá-la, além da proibição legal. Assim sendo, no início do século XVIII os problemas monetários da colônia pareciam estar solucionados se à moeda provincial acrescentarmos a produção das Minas e a retomada da cunhagem de moedas de ouro na Casa da Moeda do Rio Janeiro a partir del703.

No entanto, já na primeira década do século começam novamente a serem ouvidos reclamos, na Bahia, sobre falta de moeda. E ao longo dos Setecentos, farta correspondência entre a colônia e a metrópole registra mais queixas e novas propostas de mudanças na legislação com o objetivo de aplacar problemas percebidos na circulação monetária. As queixas sobre falta de moeda dizem respeito, em particular, à falta de moeda de prata e de cobre - e de moeda de baixo valor, em geral - e, nas Minas, sobre embaraços causados pelo uso generalizado de ouro em pó como moeda (meio de pagamento e unidade de conta).

Por que faltaria moeda em meio a tanta (pelo menos aparente) abundância de metais? A explicação mais comum é a exportação de ouro de maneira legal (déficits comerciais, arrecadação dos quintos) ou ilegal (contrabando, "descaminhos") para a Europa e para a Ásia. Não é possível, pelo menos até o momento, mensurar esse tipo de drenagem ("sangria"), mas as análises qualitativas são unânimes em afirmar que foi muito significativa. Assim, os argumentos apresentados a seguir não contestam, obviamente, o fato de que o Brasil era uma colônia explorada pela metrópole. O que se pretende é acrescentar ao debate outras questões, levantadas pela literatura in-

\footnotetext{
${ }^{23}$ Keynes (1973, p.174) equipara os conceitos de entesouramento e de preferência pela liquidez. A preferência pela liquidez, no final do século XVII, poderia estar relacionada, por exemplo, à expectativa de mais um "levantamento" da moeda (haveria assim uma "demanda especulativa" por moeda) e às perseguições aos cristãos-novos (Mello, 1996).
} 
ternacional, sobre problemas relacionados à adoção do bimetalismo. Naquele período, a "escassez de moeda" afligia corriqueiramente não apenas as colônias americanas, mas também suas respectivas metrópoles europeias, já que compartilhavam um mesmo padrão monetário bimetálico e, portanto, suas possíveis vantagens e mazelas. ${ }^{24}$

Em linhas bastante gerais, no caso brasileiro a questão poderia ser colocada da seguinte maneira. Na década de 1690 deu-se o início da produção de ouro, que se acelerou nas décadas posteriores. O aumento espetacular da oferta de ouro na colônia e na metrópole certamente desvalorizou o valor de mercado do metal frente à prata. De acordo com a lei de Gresham, a prata, assumindo a posição de "moeda boa", sairia de circulação, expulsa pela "moeda má", de ouro. Para que tal não ocorresse, seria necessário que o governo português modificasse a paridade oficial ouro/prata. As autoridades lisboetas demoraram cerca de quatro décadas para reagir (em 1734) e, quando o fizeram, a produção de ouro das Minas (hoje se sabe) estava perto do seu auge. Naquela ocasião a mudança foi de pouco mais de $10 \%$, elevando o preço do marca de prata para 6.800 réis, o que não surtiu qualquer efeito, dado que o preço de mercado era, em Portugal, ainda maior. Em 1747, foi realizado outro ajuste, que fixou o preço oferecido pelo marco de prata em 7.500 réis. Desta forma, a relação ouro/prata, que pela reforma de 1688 havia sido estabelecida em 1:15,5, passou a ser de $1: 13,2$, o que contribuiu para que, pela primeira vez no século, a Casa da Moeda de Lisboa cunhasse moeda de prata. $^{25}$

Se a conjuntura monetária no Brasil de alguma maneira reflete os eventos em Portugal, pode-se deduzir que havia também escassez de moedas de prata no Brasil. Mesmo que muitas das moedas de ouro cunhadas no Rio de Janeiro, Minas e Bahia circulassem na colônia, boa parte da população sentiria a "falta de moeda" para as transações cotidianas, em especial porque também algumas das moedas de prata (p. ex., dois vinténs, meia pataca) compunham parte do estoque do que se pode definir como "moedas de baixo valor" (a outra parte sendo composta de moedas de cobre e, na região mi-

\footnotetext{
${ }^{24}$ A situação monetária da Europa no início da Idade Moderna é descrita, em outros, por Kindleberger (1984). Um excelente resumo da evolução monetária da América inglesa é apresentado por McCusker (1978). Visões contrastantes sobre a produção de metais e monetização na América espanhola podem ser encontradas nas obras de Romano (1998) e Assadourian (1979).

${ }^{25}$ Sousa, op. cit., pp. 89-90.
} 
neira, de ouro em pó). Portanto, por ocasião da segunda (e última) mudança ocorrida em 1747, a produção de ouro ainda crescia. A partir dos anos 1760, entretanto, a mineração entrou em declínio, que não mais foi revertido. Ao mesmo tempo, retomava, em escala ainda desconhecida, a entrada de prata vinda do sul do continente, através de negócios, legais ou de contrabando, realizados entre a Colônia do Sacramento e Buenos Aires. Neste momento, é provável que a relação ouro/prata de mercado tenha favorecido de alguma maneira o ouro. Inversamente do que acontecera no início do século (ainda que sem a mesma intensidade), a ação da lei de Gresham provocaria uma retirada do ouro de circulação, no Brasil e em Portugal. Para atrair ouro, teria de haver novas mudanças na paridade ouro/prata. Contudo, de 1747 a 1822 nenhuma outra alteração na paridade oficial dos metais foi decretada.

No início do século XIX, seria escassa a circulação monetária na colônia. A explicação apresentada por diversos autores ${ }^{26}$ (que certamente não ignoravam a drenagem de moeda pela Coroa e comerciantes metropolitanos) para o fenômeno eram os efeitos da lei de Gresham e a existência de paridades diversas para o ouro e a prata.

\subsection{Primeira Metade do Século XVIII}

De acordo com Sombra (1940, p. 75),

$o$ século XVIII começa com uma grande crise de moedas de prata na Colônia. A 8 de julho de 1700, o governador Arthur de Sá e Meneses faz presente a el-rei o 'miserável estado' em que se acha o Rio de Janeiro 'com a falta de moeda de prata e miúdos'. A evasão da prata se faz para São Paulo, 'em razão dos paulistas a troco dela venderem ouro mais barato'.

Cabem duas observações sobre a citação acima. A primeira é a de que "vender ouro mais barato" é uma clara evidência da ação da lei de Gresham: no Rio de Janeiro, por onde escoava o ouro das Minas já na passagem do século, a prata tornara-se mais cara no mercado,

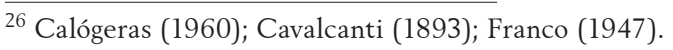


ou seja, subvalorizada oficialmente, e por isso estava sendo expulsa de circulação. A segunda é relativa à moeda de troco: em julho de 1700, a Casa da Moeda do Rio de Janeiro acabara de cunhar cerca de 2 milhões de cruzados, dos quais cerca de $70 \%$ eram moedas de ouro, o que aparentemente em nada ajudava a resolver o problema da "escassez de moeda" que oficialmente justificara a sua criação.

Numa tentativa de impedir o desaparecimento completo das moedas de prata, o governador permitiu que apenas dois ourives trabalhassem na capital fluminense e, para amenizar a escassez de moeda miúda no Brasil, Portugal enviou, em 1703, moedas de cobre com valor nominal estabelecido em X e XX réis, cunhadas em Angola. ${ }^{27}$ Mas as queixas sobre o desaparecimento da prata seguem ao longo da primeira década do século na capitania fluminense, como indica a carta do rei dirigida ao oficial da Casa da Moeda do Rio de Janeiro, Manuel de Sousa, em 21/08/1709, prometendo tomar providências acerca "da grande valia em que esses moradores tem posto a prata, de que receaes se extingua toda a moeda deste metal reduzindo-se à obra pelo grande interesse que della tirão os ourives." (Boxer, 1965, p.7)

A situação não seria diferente em outras capitanias. Para RussellWood (1981, p. 53), a "escassez de dinheiro líquido foi uma das principais razões para o declínio da prosperidade da Bahia no século XVIII". ${ }^{28}$ A queda na demanda por açúcar baiano manteve a tradição dos agentes das companhias de Lisboa de só vender produtos por moeda, e não por açúcar. Além disso, parte da moeda cunhada (portanto, de prata) foi para as Minas Gerais, levada pelos fazendeiros de gado e pelos garimpeiros. Já em 1712, a Câmara de Salvador calculava que restavam apenas 500 mil cruzados em circulação na Bahia, ${ }^{29}$ cuja Casa da Moeda, como mencionado anteriormente, havia cunhado, menos de duas décadas antes, um volume quatro vezes maior de moeda provincial.

${ }^{27}$ Novos envios de moeda de cobre chegam em 1707 e 1715, mas aparentemente Minas Gerais só recebeu a primeira remessa em 1725 ou 1730 (Sombra 1940).

${ }^{28}$ No século XVIII, comerciantes e homens de negócio passaram a ser os mais importantes testadores à Santa Casa, mas seus legados não foram tão elevados quanto os dos senhores de engenho (que predominaram no século anterior) em razão da "falta de liquidez na Bahia" (Russell-Wood, 1981, p.115).

${ }^{29}$ Vale lembrar que nem sempre esse tipo de relato espelhava a realidade. Era comum nos documentos enviados à Corte por camaristas e autoridades coloniais referências à iminente chegada da "total ruína" caso suas reivindicações não fossem atendidas. 
A análise de Russell-Wood é semelhante à de Virgílio Noya Pinto, para quem os problemas monetários na Bahia reaparecem já na primeira década do século XVIII (Pinto, 1979). O autor cita uma representação do Senado da Bahia que reporta "a falta total que se experimenta de moeda". Tal problema originava-se de "um comércio deficitário que canalizava o numerário não somente para a Europa como para a região das Minas" (p. 42). O numerário que vai para a região das Minas é obviamente de prata. Em nota de rodapé, Noya Pinto menciona documento que detalha uma operação de arbitragem: uma moeda de duas patacas (de prata), com valor extrínseco de 640 réis, podia ser trocada por uma oitava de ouro, sendo que o preço pago por uma oitava de ouro na Casa da Moeda alcançava 1200 réis. Mesmo descontando-se os custos de transporte e outros de uma viagem desde a Bahia até Minas, e de lá para o Rio de Janeiro, a transação era suficientemente lucrativa para carrear a prata da região nordeste para o sudeste. O lucro neste tipo de operação poderia continuar enquanto houvesse moeda de prata em circulação.

Em 1731, os oficiais da Câmara de Olinda requeriam que o pagamento dos donativos fosse feito em açúcar "visto a cidade não ter moeda corrente". Queixavam-se da falta de moeda de ouro, de prata e de cobre principalmente "porque a levam os comissários do negócio que para este Reino todos os anos para daqui a transportarem para o Norte, onde dizem tem maior valia, sem que possa haver remédio para se evitar semelhante danno". ${ }^{30}$

As operações de ganho com diferenças de cotações dos metais não se davam apenas com a passagem da prata nordestina para as Minas, e daí para o Rio de Janeiro. Parte dos "descaminhos" do ouro das Minas se dava a partir do seu envio para as regiões vizinhas produtoras de prata, que novamente acabavam indo para cidades portuárias e daí para a Europa ou para a Ásia. ${ }^{31}$ Maxwell (2005, p. 37) resume assim os argumentos de Alexandre de Gusmão sobre o contrabando do ouro na primeira metade do século XVIII:

${ }^{30}$ Doc. Hist. Biblioteca Nacional. Vol. C. Consultas do Conselho Ultramarino. Capitanias do Norte. Códice I-6,3,23. p. 49. Carta dos Oficiais da Câmara pedindo para pagar os donativos em açúcar "visto a cidade não ter moeda corrente" (1731) p. 85-6.

${ }^{31}$ Na primeira metade do século XVIII teria ocorrido o segundo "ciclo da prata", durante o qual o valor da prata em relação ao ouro na Ásia eleva-se substancialmente acima do verificado na Europa. O primeiro ciclo ocorrera na primeira metade do século anterior. Teriam sido as operações de arbitragem efetuadas pelos comerciantes europeus em seus negócios principalmente com a China que levaram, eventualmente, a uma equiparação da relação de preços ouro/prata nos dois continentes (Flynn \& Giraldez, 2002). 
O contrabando do ouro ia de Minas Gerais para Buenos Aires ou, assim como o proveniente de Cuiabá e Mato Grosso, para as províncias espanholas próximas. Ali era trocado a uma taxa favorável por prata, e esta voltava às cidades portuárias brasileiras, onde era usada para comprar manufaturas contrabandeadas.

Portanto, a prata não substituiria o ouro que se esvaía. Como a economia paulatinamente se internalizava e aumentava o comércio inter-regional, eram frequentes os pedidos de cunhagem de moeda provincial que atendesse à "falta de trocos para o comércio vulgar". ${ }^{32}$

A situação no Brasil espelhava a da metrópole onde "...nas décadas de 20 e 30 do século XVIII os viajantes estrangeiros dão conta da abundância de moedas de ouro em Lisboa e da escassez de moedas de prata e cobre para trocos..." (Sousa, 2006, p. 234). A falta de moeda de prata é "quase total" até 1750. Note-se que a Casa da Moeda de Lisboa não cunhou moeda de prata alguma até desde 1700 até 1747, quando o segundo "levantamento" da prata foi decretado. Mesmo assim, o efeito daquela medida foi efêmero, e três anos depois a cunhagem de prata havia sido novamente interrompida em Lisboa.

Em meados do século XVIII, a qualidade da circulação monetária é questionada pelas próprias autoridades. Em Aviso de 10/03/1751, o Rei ordena que, "atendendo [...] ao muito dinheiro que corria viciado que se faça uso de serrilhas na cunhagem de toda moeda provincial, inclusive as que vão para as Minas" (Sombra, 1940, p. 201). Poucos meses depois, decide pela recunhagem de toda a moeda antiga em circulação na Bahia para que "tenham o verdadeiro e necessário remédio as desordens que se tem introduzido no comércio por causa de muitas moedas falsas de ouro e prata. ${ }^{33}$

32 AN. Códice 952, Vol. 23, p. 296. Lei de 4 de abril de 1722, que ordenava que fossem fabricadas espécies de ouro (escudos e dobras) com valores entre 800 réis e 12\$800 réis. Como se nota, a noção de "moeda de troco" é bastante elástica, levando-se em conta que as únicas moedas de cobre em circulação no Brasil valiam até 20 réis. Ver também IHGB/AHU. Arq. 1.1.26. Representam os oficiais da Câmara do Rio de Janeiro a grande necessidade que há naquela Capitania de moeda provincial, pedindo se lhe dê providência nesta matéria. pp. 66-80v. 18/04/1730.

33 Ofício de 21/06/1751, cit. Sombra, 1940, p.41. 


\subsection{Segunda Metade do Século XVIII}

A alteração na relação oficial entre os preços do ouro e da prata efetuada em 1747 teve o propósito de adequar o preço oficial ao preço de mercado. Em Portugal, de acordo com Sousa (2006), o resultado concreto da medida foi que, durante três anos, chegou à Casa da Moeda de Lisboa alguma prata para ser cunhada. As entradas de ouro naquele estabelecimento começavam a cair e, principalmente a partir do final da década de 1750, as entradas de prata novamente aumentaram, ainda que de maneira irregular, já que dependiam em parte da chegada de prata do Brasil. ${ }^{34}$ Contudo, "na análise da composição da amoedação verificamos que a cunhagem de moedas de prata de pequeno valor facial, as designadas 'moedas de troco', foi percentualmente baixa" Sousa (2006, p. 236).

No Brasil, também naquele período, a prata vinda de Sacramento voltou a ser cunhada. ${ }^{35}$ Tratava-se, portanto, de recunhagem de patacas, com valor nominal mais elevado (moeda provincial). O retorno da prata legal ou ilegalmente trazida da América espanhola poderia em parte ser explicada pelo grande crescimento da produção daquele metal em Potosi e no México, enquanto caía a produção de ouro no Brasil. Para os homens de negócio continuava a ser lucrativo trocar seu ouro pela prata, que aqui continuava a valer mais do que o preço oficial. Para comerciantes das colônias espanholas, por sua vez, o ouro tornou-se ainda mais atraente, principalmente após a mudança da relação oficial ouro/prata ter sido elevada para 1:16 em 1750 na América espanhola e em 1772 na Espanha. ${ }^{36}$

${ }^{34}$ Entre 1765 e 1770, a maior parte da prata entrada na Casa da Moeda é originada de remessas nas naus saídas do RJ (Sousa, 2006, p. 114).

${ }^{35}$ Entre 1748 e 1750 foram cunhadas moedas de prata de valores entre 80 e 640 réis no Rio de Janeiro; entre 1753 e 1777, as Casa da Moeda do Rio de Janeiro e da Bahia cunharam moedas de prata também com valores de 75, 150, 300 e 600 réis, com o intuito de resgatar ouro em pó. Entre 1777 e 1804 o resgate do ouro em pó não é mais mencionado. A Casa da Moeda da Bahia foi a única que cunhou moedas de cobre (Galvão, 1905). Todas as moedas de prata e de cobre cunhadas nestas duas casas da moeda eram moedas provinciais, com valor intrínseco inferior ao seu equivalente em Portugal e aquelas com valor nominal inferior a 100 réis poderiam ser consideradas de baixo valor, ou "de troco". De qualquer forma, cabe lembrar que todas as moedas provinciais, mesmo as de ouro, eram cunhadas tendo em vista sua circulação exclusiva na colônia. O objetivo explícito da emissão de moeda provincial era atender as necessidades do "giro do comércio" interno, enquanto que o da emissão de moedas nacionais (de ouro, de valor muito elevado) era o de remetê-las para a metrópole.

${ }^{36}$ Hamilton (1944). O governo espanhol tinha interesse em atrair ouro, na medida em que era mais fácil e mais barato pagar seus soldados que lutavam fora da Espanha em moedas de ouro do que em moedas de prata. 
Os ganhos com o câmbio, portanto, eram atraentes. Enviava-se ouro - que, longe das Minas e perto do Prata valia mais - e trazia-se prata. Em tese, enquanto a diferença fosse superior aos custos de transação, no Rio de Janeiro entraria prata e sairia ouro (e vice-versa na região do Rio da Prata) até que não fizessem mais sentido as operações de arbitragem. Relatando a situação referente à década de 1790 no extremo sul do Brasil, Menz (2009, p. 114) constata que

a principal origem das moedas que permitiam ao Rio Grande saldar suas contas com o Rio de Janeiro era o contrabando com a região platina [...] já que 2/3 das moedas remetidas pelo Rio Grande eram de prata. O negócio da prata incentivava os comerciantes rio-grandenses a trazer ouro das praças nordestinas e do interior do Brasil, assim poderiam ganhar no câmbio e pagar com vantagem seus fornecedores...

Todavia, não havia incentivos para que estas moedas fossem levadas para serem recunhadas na Casa da Moeda em grandes quantidades porque esta oferecia 108 réis por oitava, enquanto que o mercado oferecia até 112 réis. Mais ainda, havia incentivo para enviá-la para Lisboa, onde a diferença seria ainda maior e de onde seguiria para o Oriente (Santos, 1998). A pequena amoedagem de prata no Brasil devia-se também às características físicas da moeda. Os registros de envio de prata para Lisboa referem-se a "piastras" e "pesos", na época uma moeda aceita em toda parte do mundo; não fazia sentido, portanto, enviar moedas de prata fabricadas no Brasil (Godinho, 1983; Pinto, 1979). Por outro lado, as moedas de prata tinham baixo valor nominal e por esta razão sua cunhagem rendia baixa receita de senhoriagem às Casas da Moeda quando comparada às de ouro. ${ }^{37}$

Nos primeiros anos do século XIX, a escassez de moeda metálica no Brasil seria generalizada, de acordo com os (poucos) autores que trataram do tema. ${ }^{38}$ Pelos cálculos de Amaro Cavalcanti, ${ }^{39}$ haveria em

${ }^{37}$ Como relata o governador da Bahia D. José Fernando de Portugal, em 1797, "também se cunhou em outro tempo [final do século XVII] moeda de prata do valor de $\$ 020$ [vintém] e do valor de \$ 040 que hoje são raras e que há muitos anos não se cunham, por serem demasiadamente pequenas, pouco rendosa a senhoriagem à proporção de trabalho que se emprega em seu cunho", cit. em Sombra, 1940, p. 73.

38 Ver Oliveira (1842); Cavalcanti (1893); Calógeras (1960); Franco (1947).

39 Cavalcanti (1893). Esta estimativa tem sido aceita desde então por diversos autores. 
circulação um total de 10 mil contos, dos quais $2 / 3$ seriam moedas de ouro e o restante de prata e de cobre. A velocidade de circulação da moeda seria baixa, devido à tendência ao entesouramento. Essa moeda, de qualquer forma, concentrava-se nos centros maiores (principalmente cidades portuárias) porque, nas Minas Gerais, desde sempre, o meio de pagamento era quase exclusivamente o ouro em pó. ${ }^{40}$ Uma das causas apontadas por aqueles autores (inclusive o papelista Amaro Cavalcanti) era o efeito da lei de Gresham causado pela existência de paridades diversas da moeda de ouro e desta com a moeda de prata. A relação de mercado (prevalecente na Europa) seria de 1:15,5, enquanto que as duas relações oficiais (moedas de ouro nacional e provincial) era de 1:12 e 1:14, respectivamente, fazendo com que a moeda sobrevalorizada fosse a de prata (Cavalcanti, 1893, pp. 6-7).

Verificava-se, portanto, uma situação inversa daquela registrada no início do século XVIII, quando era o ouro que tinha seu valor oficial fixado acima do de mercado, e a prata acabou expulsa. Nos primeiros anos do século XIX, a saída de ouro seria uma questão de tempo, como argumenta a posteriori o autor de Systema Financial do Brasil:

um estado de circulação monetária tão absurdo [...] como bem se pode presumir [...] apenas se franquearam os portos do Brasil ao commercio estrangeiro, o qual bem depressa fez desaparecer do mercado as espécies de ouro, legalmente depreciadas em relação à moeda de prata. (Cf. Cavalcanti, idem, p. 7)

Segundo Calógeras (p. 22), o fato de, no início do século XIX, ainda circular uma proporção considerável de moedas de ouro, "por curiosa contradição da lei de Gresham" se explicaria pelas restrições comerciais, pela escassez de prata e pela falta de informação.

${ }^{40}$ Embora este trabalho não discuta a circulação do ouro em pó, vale registrar a observação de Severino Sombra de que o ouro em pó fazia o papel de moeda má no funcionamento da lei de Gresham (Sombra, 1940). 


\section{Considerações Finais}

Um sistema monetário baseado em moedas de diferentes metais, tal como o vigente desde a Idade Média até o século XIX, exige o uso, em paralelo, de metais mais e menos valorizados - especificamente, ouro, prata e cobre. A descoberta de ouro e a grande cunhagem de espécies deste metal nas casas da moeda contribuíram para elevar o nível de monetização do Brasil no século XVIII, mas não poderiam ter sido suficientes para solucionar definitivamente os problemas típicos de um sistema bimetálico, em particular aqueles trazidos pela ação da lei de Gresham.

Durante praticamente toda a primeira metade do século XVIII, a prata comprava mais ouro no mercado do que oficialmente. Todo o incentivo era, portanto, para entesourar a prata, ou exportá-la. A exportação podia se dar da região Bahia e de Pernambuco (onde nos derradeiros anos do século XVII foi amoedado um considerável volume deste metal) para a região das Minas. Ou podia ser exportado para a Ásia, após ser adquirido na América espanhola em troca do ouro mineiro. A segunda (e última) alteração na relação ouro/prata, decretada em 1747, não deve ter sido suficiente para reverter de imediato esse quadro.

Desde então, e até o final do século XVIII, a queda na produção de ouro nas Minas e o aumento da saída deste metal da colônia, que ocorreram concomitantemente com o aumento (ainda que espasmódico) da oferta de prata, devem ter pouco a pouco reduzido essa discrepância entre os valores oficiais e de mercado do ouro e da prata. No início do século XIX, em função da maior valorização do ouro internacionalmente, a prata estaria se tornando a "moeda má", prestes a expulsar a de ouro.

\section{Referências}

ÁLVAREZ-NOGAL, Carlos. Spanish monarchy's monetary problems in the seventeenth century: small change or foreign credit. Universidad Carlos III. Working Paper 03-09. Economic History and Institutions Series 5, 2003.

ASSADOURIAN, Carlos S. La producción de la mercancia dinero en la formación del mercado interno colonial. In: FLORESCANO, Enrique. (comp.) Ensayos sobre el desarrollo económico de México y de América Latina (1500-1975). México: Fondo de Cultura Económica, 1979. 
BORDO, Michael. Bimetallism. In The New Palgrave Dictionary of Money and Finance. Newman, P., Milgate, M. \& Eatwell, J (Ed.). London: Macmillan, 1992.

BOXER, Charles R. Brazilian gold and British traders in the first half of the eighteenth century. Hispanic American Historical Review, vol. 49, n.3, 1969.

. Catálogo das cartas dirigidas a Manuel de Sousa, oficial das Casas da Moeda do Brasil, 16951721. Revista do Instituto Histórico e Geográfico Brasileiro, vol. 266, 1965.

CALÓGERAS, Pandiá. A Política Monetária do Brasil. São Paulo: Companhia Editora Nacional, 1960.

CARRARA, Angelo Alves. Amoedação e oferta monetária em Minas Gerais: as Casas de Fundição e Moeda de Vila Rica. Varia Historia, BH, V. 26, n.43, jan/jun, 2010.

. Ouro, moeda e mercado interno: um modelo contábil da economia de Minas Gerais, 1700-1808. UFJF, Depto de História Working Paper 02-07 (2005).

CAVALCANTI, Amaro. O Meio Circulante, Primeiro Volume (1808 a 1835). Rio de Janeiro: Imprensa Nacional, 1893.

CIPOLLA, Carlo M. Money, Prices and Civilization in the Mediterranean World: Fifth to Seventeenth Century. New York: Gordian Press, 1967.

ENNIS, Huberto N. The problem of small change in early Argentina. Federal Reserve Bank of Richmond Economic Quarterly, vol. 92/2, 2006.

FLANDREAU, Marc. The French crime of 1873: An essay on the emergence of the international gold standard, 1870-1880. The Journal of Economic History, vol.56, n.4, 1996.

FLANDREAU, Marc. "Water seeks a level": Modeling bimetallic exchange rates and the bimetallic band. Journal of Money, Credit and Banking, vol.34, n.2, 2002.

FLYNN, Dennis O. \& GIRALDEZ, Arturo. Cycles of silver: Global economic unit through the mid-eighteenth century. Journal of World History, vol.13. n.2, 2002.

FRANCO, Afonso Arino de Melo. História do Banco do Brasil, Primeira Fase, 1080-1835. São Paulo: Instituto de Economia da Associação Comercial de São Paulo, 1947.

FRIEDMAN, Milton. The crime of 1873. Journal of Political Economy, vol. 98, n.6, 1990.

GALVÃO, M. A. Amoeda no Brazil. Revista do Instituto Historio e Geográfico, Tomo LXVI, Parte II, 1905.

GLASSMAN, Deborah \& REDISH, Angela. Currency depreciation in early modern England and France. Explorations in Economic History, vol. 25, 1988.

GODINHO, V. M. Portugal, as frotas de açúcar e as frotas do ouro (1670-1770). Estudos Econômicos, n.13 (Especial), 1983.

GONÇALVES, Cleber Baptista. Casa da Moeda, 290 Anos de História, 1694-1984. Rio de Janeiro (1984).

HAMILTON, Earl J. Monetary problems in Spain and Spanish America, 1750-1800. The Journal of Economic History, vol 4. n.1, 1944.

KEMMERER, Edwin W. Money: The Principles of Money and their Exemplification in Outstanding Chapters of Monetary History. New York: MacMillan, 1935.

KINDLEBERGER, Charles P. A Financial History of Western Europe. London: George Allen \& Unwin, 1984.

LIMA, Fernando C. G. de Cerqueira. Uma análise critica da literatura sobre a oferta e a circulação de moeda metálica no Brasil nos séculos XVI e XVII. Estudos Econômicos. Vol. 35, nº 1, 2005a.

- A Lei de Cunhagem de 4 de agosto de 1688 e a emissão de moeda provincial no Brasil (16951702): um episódio da história monetária do Brasil. Revista de Economia Contemporânea. Vol. 9, N.2, Maio-Agosto de 2005b.

MAURO, Frederic. Portugal, o Brasil e o Atlântico, 1570-1670, Vol. 2. Lisboa: Editorial Estampa, 1997.

MAXWELL, Kenneth. A Devassa da Devassa. A Inconfidência Mineira: Brasil e Portugal, 1750-1808.

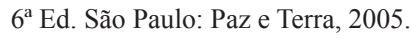


McCUSKER, John J. Money and Exchange in Europe and America, 1600-1775. Virginia: Chapel Hill, 1978. MELLO (1996), Carl E. H. Vieira de. O Rio de Janeiro no Brasil Quinhentista. São Paulo: Giordano, 1996.

MENZ, Maximiliano M. Entre Impérios: Formação do Rio Grande na Crise do Sistema Colonial Português (1777-1822). São Paulo, Alameda, 2009.

MUNDELL, Robert. Uses and abuses of Gresham's law. Zagreb Journal of Economics, vol.2, n.2, 1998.

OLIVEIRA, Candido Baptista de. Systema Financial do Brasil. S. Petersburgo: Typographia Privilegiada de Fischer, 1842.

PERES, Damião. História de Portugal. Vol. 6. Barcelos: Braga: Portucalense, 1934.

PINTO, Virgílio Noya. O Ouro Brasileiro e o Comércio Anglo-Português. São Paulo: Ed. Nacional, 1979.

PUNTONI, Pedro. O "mal do Estado Brasílico": a Bahia na crise final do século XVII. Segundo Congresso Latino-americano de Historia Econômica (CLADHE-II). México, 2010.

REDISH, Angela. The evolution of the gold standard in England. The Journal of Economic History, vol. 50, n.4, 1990.

ROMANO, Ruggiero. Moneda, seudomonedas y circulación monetária en las economias de México. Mexico: Fundo de Cultura Económica, 1998;

RUSSELL-WOOD, A.J.R. Fidalgos e Filantropos: A Santa Casa da Misericórdia da Bahia, 1660-1755. Brasília: Ed. Universidade de Brasília, 1981.

SAMPAIO, Antonio Carlos Jucá. Crédito e circulação monetária na colônia: o caso fluminense, 16501750. Anais do V Congresso Brasileiro de História Econômica. ABPHE, 2003.

SANTOS, Corcino Medeiros. A Produção de Prata das Minas do Alto Peru e a Evasão de Prata para o Peru. Brasília: Thesaurus, 1998.

SARGENT, Thomas, J.; VELDE, François. The evolution of small change. Federal Reserve Bank of Chicago, Working Paper Series, 1997.

SELGIN, George. The institutional roots of Great Britain's "big problem of small change". European Review of Economic History, vol 14, n. 2, 2010.

SOMBRA, Severino. Pequeno Esboço de História Monetária do Brasil Colonial. Rio de Janeiro: Imprensa Nacional, 1940.

SOUSA, Rita Martins de. Moeda e Metais Preciosos no Portugal Setecentista, 1688-1797. Lisboa: Imprensa Nacional - Casa da Moeda, 2006.

VAN DER WEE, Herman. Monetary, credit and banking systems. In. E. E. Rich \& C.H. Wilson. The Cambridge Economic History of Europe. Cambridge: Cambridge UP, 1977.

VELDE, François. Chronicles of a deflation unforetold. Federal Reserve Bank of Chicago Working Paper Series WP 06-12, 2006.

The crime of 1873: Back to the scene. Federal Reserve Bank of Chicago, Working Paper Series 2002-29, 2002.

VOLKART, Oliver. "The big problem of small change" and how it could be solved in the late Middle Ages. London School of Economics Working Papers n. 107/08, 2008.

WOLTERS, Williem G. Managing multiple currencies with units of account: Netherlands India, 16001800. XIV International Economic History Congress, Helsinki, Finland, 2006. 